\title{
Cytogenetic abnormalities and azoospermia factor (AZF) microdeletions in infertile men from Kuwait
}

\author{
Moussa Alkhalaf ${ }^{1}$ and Kamal Al-Shoumer ${ }^{2}$ \\ ${ }^{1}$ Departments of Biochemistry and ${ }^{2}$ Department of Medicine, Faculty of Medicine, Kuwait University, Kuwait \\ *Correspondence to: Moussa Alkhalaf, E-mail: alkhalaf@hsc.edu.kw, Tel: +965 24986433, Fax: +965 25338908
}

Received 23 February 2010, Revised 29 March 2010, Accepted 13 April 2010, Published online 26 April 2010

J Mol Genet Med, 2010, Vol 4, 232-234

(C) Copyright The Authors: This is an open access article, published under the terms of the Creative Commons Attribution Non-Commercial License (http://creativecommons.org/licenses/by-nc/2.0/uk/). This license permits noncommercial use, distribution and reproduction of the article, provided the original work is appropriately acknowledged with correct citation details.

Approximately $15 \%$ of couples in the reproductive age group worldwide are affected by infertility, and it is estimated that about $40-50 \%$ of infertilities are of male origin. Genetic factor accounts for $10-15 \%$ of severe male infertility, including chromosomal aberrations and single gene mutations (Ferlin et al, 2006). After the Klinfelter syndrome, Y chromosomal microdeletions are the most frequent genetic cause of male infertility (Krausz and Degl'Innocenti, 2006). The three regions, referred to as "azoospermia factors" (AZFa, AZFb and AZFc from proximal to distal) has been defined as spermatogenesis loci (Vogt et al, 1996). In Kuwait, male factor is accounted for infertility in over $40 \%$ of couples: the causative factors of this include oligozoospermia, asthenozoospermia and azoospermia (Omu et al, 1999). Previously, we demonstrated that chromosomal aberrations were found in $11 \%$ of couples with infertility and reproductive disorders (Alkhalaf et al, 2002). The aim of this study was to analyze the frequency of cytogenetic chromosomal abnormalities and to provide information on the type and prevalence of $\mathrm{Y}$ chromosome microdeletions in infertile males that show normal karyotypes. Y-chromosome microdeletions are specific for spermatogenic failure as no deletions have been reported in a large number of normospermic men (Vogt, 2005). Delineating the genetic basis of male nfertility in our population is important in view of the most recent advances in reproductive technologies, which have already been initiated in Kuwait.

The patient group included in this study were 142 Kuwaiti men with confirmed idiopathic infertility for at least 2 years (aged 20-48 years; mean age $=28$ years). As controls, we recruited 166 Kuwaiti men (aged 21-50 years; mean age $=32$ years) with proven fertility but with two or more children. Patients selection criteria included the presence of azoospermia, severe oligozoospermia (sperm concentration $<5 \mathrm{million} / \mathrm{ml}$ ), testicular phenotype of Sertoli cell only syndrome or severe hypospermatogenesis.
This study was approved by the ethical committee of the Faculty of Medicine, Kuwait University and the Kuwaiti Health Ministry, and was in accordance with the Helsinki II declaration. Chromosomal analysis was performed on cultures of peripheral blood lymphocytes from patients as described previously (Alkhalaf et al, 2005). For each patient at least 30 well-spread metaphases were analyzed. When cytogenetic abnormalities are detected in the patient the number of analyzed metaphases was increased to 50 metaphases. DNA was extracted with PUREGEN DNA Purification Kit (Gentra system, Minneapolis, USA). Molecular analysis for AZF loci was done using multiplex PCR (Table I) as previously (Simoni et al, 2004). In parallel with the patient DNA samples, fertile male and female samples were used as positive and negative controls, respectively. In each PCR reaction two blank samples were employed as negative controls, to eliminate the possibility of contamination.

Chromosomal karyotyping of 142 patients revealed somatic anomalies in 26 infertile male (26/142=18.3\%) (Table II). The most common chromosomal abnormality was Klinefelter's syndrome which showed 47,XXY karyotype $(16 / 142=11.27 \%)$. One patient showed a variant Klinefelter's syndrome with the 46,XX [49]/47,XXY [4] karyotype. Overall, Klinefelter's syndrome cases counted for more than half of the chromosomal abnormalities $(17 / 26=65 \%)$. Two patients showed 46,XYqh ${ }^{-}$karyotype (polymorphic variants) and one patient with 46,XYqh ${ }^{-}$ 145,XO karyotype. Two patients showed a small deletion in the small arm of chromosome 21. Each of the following karyotypes were detected once: 46, XX male, 46, XY +ive marker, 45,XY,-14,-21,+t(14;21) and 45,XY,-14,$13,+t(14 ; 13)(q 11 ; q 11)$. Please check these are correct!

Microdeletions in Y-chromosome were not detected in any of the 26 cytogenetically abnormal subjects. Of the 126 infertile patients with normal karyotypes, nine had 
microdeletions in Yq-chromosome (9/126=7.14\%) (Table III). The most frequent deletion was in AZFc region (5/9=55.6\%), followed by AZFb-c region ( $3 / 9=33.3)$ and AZFa region $(1 / 9=11.1)$. The AZFb deletion was not detected in our patients.

Previous studies (Nakamura et al, 2001; Poongothai et al, 2009) for different populations have shown that the incidence of chromosomal abnormality in infertile males was between $2.2 \%$ and $19.6 \%$. The most common chromosomal abnormality in these studies was Klinefelter's syndrome followed by $\mathrm{Yq}$ deletions (Poongothai et al, 2009). Our study shows that the incidence of chromosomal abnormalities in infertile Kuwaiti men was $18.3 \%$ (26/142). $81.7 \%$ of patients showed a normal male karyotype (116/142). The 47.XXY genotype accounted for $50 \%$ of cytogenetic abnormalities (13/142=9.5\%). Cytogenetic findings in the Kuwaiti patients were in accordance with previously published findings (Elghezal et al, 2006; Chantot-Bastaraud et al, 2008). None of the 26 cases with chromosomal abnormalities had Yq microdeletions. However, 9 out of 116 infertile males with normal karyotype showed Yq microdeletions. Our study showed that 7 of the cases with the $\mathrm{Yq}$ microdeletions had azoospermia and 2 cases had severe oligozoospermia. Five out of nine men had the presence of $\mathrm{Yq}$ microdeletions confined to the AZFc region. These data support earlier studies that azoospermic men had higher frequency of microdeletions than oligospermic men, and those men with deletions in the AZFc region were the most common in several populations (Elghezal et al, 2006; Chantot-Bastaraud et al, 2008). The three other $\mathrm{Yq}$ microdeletions are in the AZFa-c region and were present in azoospermic patients. Only one case harbored a deletion in the AZFa region. None of our cases had a deletion in the AZFb region. Our data on the Kuwaiti patients confirmed the recent findings of Mohammed and colleagues (Mohammed et al, 2007) who reported similar cytogenetic and molecular abnormalities in infertile Kuwaiti patients.

In conclusion, our data show that the pattern and prevalence of chromosomal abnormalities and $\mathrm{Yq}$ microdeletions in infertile Kuwaiti men were comparable within infertile groups from other Asian and Western countries. In Kuwait, most men with Yq microdeletions require ICSI to overcome their infertility. These findings can form an important component of genetic counselling to Kuwaiti men with Yq microdeletions.

\section{ACKNOWLEDGMENTS}

This study was supported by Kuwait University Research Administration Grants MB01/07 and GM 01/05.

\section{COMPETING INTERESTS}

None declared.

Table 1. Primer sequence of the sequence-tagged-sites (STSs) used in the detection of AZF loci (AZFa, AZFb and AZFc) and SRY. Multiplex PCR A primers were used to screen all samples, multiplex PCR B primers were used to confirm the deletions observed in multiplex PCR A reaction.

\begin{tabular}{|c|c|c|c|}
\hline STS & Sequence $5^{\prime} \rightarrow 3$ ' & Locus & Size (bp) \\
\hline \multicolumn{4}{|c|}{ Multiplex PCR A } \\
\hline sY86-F & GTG ACA CAC AGA CTA TGC TTC & AZFa & 320 \\
\hline sY86-R & ACA CAC AGA GGG ACA ACC CT & & \\
\hline sY127-F & GGC TCA CAA ACG AAA AGA AA & AZFb & 274 \\
\hline sY127-R & CTG CAG GCA GTA ATA AGG GA & & \\
\hline sY254-F & GGG TGT TAC CAG AAG GCA AA & AZFc & 400 \\
\hline sY254-R & GAA CCG TAT CTA CCA AAG CAG C & & \\
\hline sY14-F & GAA TAT TCC CGC TCT CCG GA & SRY & 495 \\
\hline sY14-R & GCT GGT GCT CCA TTC TTG AG & & \\
\hline \multicolumn{4}{|c|}{ Multiplex PCR B } \\
\hline sY84-F & AGA AGG GTC TGA AAG CAG GT & AZFa & 326 \\
\hline sY84-R & $\begin{array}{l}\text { GCC } \\
\text { TAC }\end{array}$ & & \\
\hline sY134-F & GTC TGC CTC ACC ATA AAA CG & AZFb & 301 \\
\hline sY134-R & ACC ACT GCC AAA ACT TTC AA & & \\
\hline sY255-F & 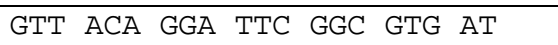 & AZFc & 126 \\
\hline sY255-R & CTC GTC ATG TGC AGC CAC & & \\
\hline sY14-F & GAA TAT TCC CGC TCT CCG GA & SRY & 495 \\
\hline sY14-R & GCT GGT GCT CCA TTC TTG AG & & \\
\hline
\end{tabular}


Table 2. Cytogenetic abnormalities observed in 142 infertile men.

\begin{tabular}{|l|l|l|}
\hline Karyotype & Number of cases (\%) & $\begin{array}{l}\text { Y Chromosome } \\
\text { microdeletions }\end{array}$ \\
\hline $47, \mathrm{XXY}$ & $16(11.27 \%)$ & None \\
\hline $46, \mathrm{XX}[49] / 47, \mathrm{XXY}[4]$ & $1(0.7)$ & None \\
\hline $46, \mathrm{XY}$ qh- & $2(1.4)$ & None \\
\hline $46, \mathrm{XY}$ qh-/45X & $1(0.7)$ & None \\
\hline $46, \mathrm{XX}$ male & $1(0.7)$ & None \\
\hline $46, \mathrm{XY}$; 21p- & $2(1.4)$ & None \\
\hline $46, \mathrm{XY}+$ marker & $1(0.7)$ & None \\
\hline $45, \mathrm{XY},-14,-21,+\mathrm{t}(14 ; 21)$ & $1(0.7)$ & None \\
\hline $45, \mathrm{XY}-14,-13,+\mathrm{t}(14 ; 13)(\mathrm{q} 11 ; \mathrm{q} 11)$ & $1(0.7)$ & None \\
\hline & & \\
\hline $46, \mathrm{XY}$ Normal male karyotype & $126 / 142(81.7 \%)$ & $9 / 126(7.1 \%)$ \\
\hline Abnormal Karyotype & $26 / 142(18.3 \%)$ & $0 / 26(0 \%)$ \\
\hline
\end{tabular}

Table 3. Characteristics of infertile men with Yq microdeletion.

\begin{tabular}{|l|l|l|l|}
\hline Patient & $\begin{array}{l}\text { Age } \\
\text { (Year) }\end{array}$ & Diagnosis & Deletion \\
\hline 1 & 31 & Azoospermia & AZFa \\
\hline 2 & 26 & Azoospermia & AZFc \\
\hline 3 & 28 & Azoospermia & AZFc \\
\hline 4 & 30 & Oligozoospermia & AZFc \\
\hline 5 & 32 & Azoospermia & AZFc \\
\hline 6 & 35 & Oligozoospermia & AZFc \\
\hline 7 & 28 & Azoospermia & AZFb-c \\
\hline 8 & 29 & Azoospermia & AZFb-c \\
\hline 9 & 40 & Azoospermia & AZFb-c \\
\hline
\end{tabular}

AZF: Azoospermia factor

\section{REFERENCES}

Ferlin A, Arredi B, Foresta C. 2006. Genetic causes of male infertility. Reprod Toxicol, 22, 133-141.

Krausz C, Degl'Innocenti S. 2006. Y chromosome and male infertility: update. Front Biosci, 11, 3049-3061.

Vogt PH, Edelmann A, Kirsch S, et al. 1996. Human Y chromosome azoospermia factors (AZF) mapped to different subregions in Yq11. Hum Mol Genet, 5, 933-943.

Omu AE, Ismail AA, Al-Qattan F. 1999. Infertility in Kuwait. Int J Gynaecol Obstet, 67, 113-114.

Alkhalaf M, Verghese L, Muharib N. 2002. A cytogenetic study of Kuwaiti couples with infertility and reproductive disorders: short arm deletion of chromosome 21 is associated with male infertility. Ann Genet, 45, 147-149.

Vogt PH. 2005. Azoospermia factor (AZF) in Yq11: towards a molecular understanding of its function for human male fertility and spermatogenesis. Reprod Biomed Online, 10, 81-93.
Simoni M, Bakker E, Krausz C. 2004. EAA/EMQN best practice guidelines for molecular diagnosis of $y$-chromosomal microdeletions. State of the art 2004. Int J Androl, 27, 240-249. Nakamura Y, Kitamura M, Nishimura K, et al. 2001. Chromosomal variants among 1790 infertile men. Int J Urol, 8, 49-52.

Poongothai J, Gopenath TS, Manonayaki S. 2009. Genetics of human male infertility. Singapore Med J, 50, 336-347.

Elghezal H, Hidar S, Braham R, et al. 2006. Chromosome abnormalities in one thousand infertile males with nonobstructive sperm disorders. Fertil Steril, 86, 1792-1795.

Chantot-Bastaraud S, Ravel C, Siffroi JP. 2008. Underlying karyotype abnormalities in IVF/ICSI patients. Reprod Biomed Online, 16, 514-522.

Mohammed F, Al-Yatama F, Al-Bader M, et al. 2007. Primary male infertility in Kuwait: a cytogenetic and molecular study of 289 infertile Kuwaiti patients. Andrologia, 39, 87-92. 